\title{
0 ensino de pediatria na atenção básica em saúde entre as fronteiras do modelo biomédico e a perspectiva da integralidade do cuidado: a visão dos médicos supervisores"
}

\author{
Alice Yamashita Prearo ${ }^{1}$ \\ Agueda Beatriz Pires Rizzato ${ }^{2}$ \\ Sueli Terezinha Ferreira Martins ${ }^{3}$
}

PREARO, A.Y.; RIZZATO, Á.B.P.; MARTINS, S.T.F. Pediatrics teaching in primary heath care between the boundaries of the biomedical model and the perspective of integrality of care: the view of the supervisor doctors. Interface - Comunic., Saude, Educ., v.15, n.39, p.1039-51, out./dez. 2011.

This is a study on medical education that focuses on pediatrics teaching in primary care. The aim is to analyze the contribution of the discipline of Social and Community Pediatrics in the $4^{\text {th }}$ year of the Medicine undergraduate course at the Botucatu Medical School,

Universidade Estadual Paulista. This qualitative research was based on a case study. The analysis was grounded on the social-historical approach, according to Vygotsky's studies. We found out what the supervisors considered to be relevant learning to their contribution to the mediation process so that students can learn about work at primary health care, something that they would not be able to reach by themselves. The interviews with the doctors revealed signification nuclei which are common to all these actors: the importance of the diversification of teaching scenarios, learning the main health problems, integral childcare with emphasis on the bond, and the student's opportunity to learn about health promotion.

Keywords: Medical education. Pediatrics. Primary health care. Case studies.
Trata-se de estudo sobre educação médica, focalizado no ensino de pediatria na atenção básica, com o objetivo de analisar a contribuição da disciplina de Pediatria Social e Comunitária no $4^{\circ}$ ano de graduação em medicina da Faculdade de Medicina de Botucatu, Universidade Estadual Paulista.Utilizou-se metodologia qualitativa de pesquisa, tendo como estratégia o estudo de caso. A análise foi fundamentada na abordagem sóciohistórica, subsidiada pelos estudos de Vigotski. Identificou-se o que os supervisores consideraram como aprendizados relevantes a sua contribuição no processo de mediação para que os estudantes aprendam sobre o processo de trabalho na atenção básica, o que não poderiam alcançar sozinhos. As entrevistas transcritas revelaram núcleos de significação comuns: importância da diversificação de cenários de ensino, aprendizado dos principais problemas de saúde, integralidade no atendimento da criança, com ênfase no vínculo e oportunidade do estudante aprender sobre promoção da saúde.

Palavras-chave: Educação médica. Pediatria. Atenção primária à saúde. Estudos de caso.

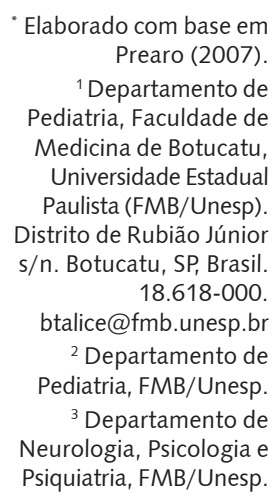

${ }^{3}$ Departamento de Neurologia, Psicologia e Psiquiatria, FMB/Unesp. 


\section{Introdução}

A diversificação de cenários na educação dos profissionais da saúde é uma tendência destacada nas diretrizes curriculares do curso de Medicina (Brasil, 2001). Entretanto, vários autores têm enfatizado que a mudança de cenário simplesmente não garante a formação de um profissional capaz de reconhecer e atuar considerando as necessidades de saúde da população (Pontes, Rego, Silva Júnior, 2006; Bulcão, 2004; Garcia, 2001; Feuerwerker, 1998). Assim, evidencia-se a importância de estudos que sinalizem o que é necessário, do ponto de vista do ensino médico, para se alcançarem transformações no perfil do profissional de saúde que se está formando.

Campos (2005), ao apresentar um documento preliminar para discutir diretrizes para o ensino médico na rede básica de atenção primária à saúde em todas as regionais da Associação Brasileira de Educação Médica (ABEM), sustenta que, na Atenção Básica à Saúde (ABS), deveriam ser resolvidos $80 \%$ dos problemas de saúde da população. Segundo o autor, colocam-se, para a ABS, três funções importantes: o acolhimento à demanda; a busca ativa com avaliação de vulnerabilidade, e a clínica ampliada que leva o profissional a intervir sobre a dimensão biológica ou orgânica de riscos ou doenças. Devem-se considerar não só as dimensões sociais bem como as da subjetividade e da saúde coletiva, realizando procedimentos de cunho preventivo e de promoção à saúde, no seu território.

Em estudo da Organização Pan-Americana de Saúde (OPAS) sobre o ensino de pediatria em escolas de medicina da América Latina, com participação de 194 faculdades ou escolas de medicina, Puga e Benguigui (2003) recomendam aumentar a prática que o aluno realiza fora do hospital, incluindo práticas sociais, comunitárias e em nível primário de atenção. A ampliação do tempo desta prática justifica-se pelo fato de permitir ao aluno aprender sobre o processo de atenção de forma integrada, incluindo aspectos de prevenção e promoção da saúde.

Tendo em vista a prática de ensino do Departamento de Pediatria da Faculdade de Medicina, UnespBotucatu, em atenção básica desde 1994, com apoio da literatura acima citada e sob a luz das recomendações da OPAS e ABEM, o presente trabalho analisou a contribuição da disciplina de Pediatria Social e Comunitária para um ensino, na graduação, que se destina à integralidade do cuidado na Atenção Básica à Saúde.

\section{A disciplina de Pediatria na Comunidade - o caso em estudo}

Desde sua implantação, em 1963, a Faculdade de Medicina de Botucatu (FMB) vem aprimorando e promovendo o diálogo entre a universidade, a comunidade e os serviços de saúde, formando profissionais e realizando estudos que contribuam para a melhoria da qualidade dos serviços de saúde oferecidos à população e para a transformação social (Cyrino, 2005).

A integração do aluno de graduação em pediatria fora do ambiente do Hospital Escola e de seus ambulatórios iniciou-se em 1994, quando passou a ter alunos do $4^{\circ}$ ano de Medicina atuando em Unidades Básicas de Saúde Municipais, de forma contínua, com supervisão dos médicos pediatras dos serviços (aqui denominados médicos supervisores) e coordenação de docente do Departamento de Pediatria. São pequenos grupos de sete a oito alunos, distribuídos em três Unidades Básicas de Saúde (UBS), participando do atendimento à criança e ao adolescente, e realizando atividades com a Equipe Multiprofissional de Saúde Escolar do Município de Botucatu que atua junto à comunidade em programas de Educação em Saúde.

Os médicos pediatras, que, desde o início, se dispuseram a receber alunos nas UBS Municipais, eram, em sua maioria, profissionais formados pela Faculdade de Medicina de Botucatu.

Todas as atividades a serem desenvolvidas foram previamente discutidas e, posteriormente, construídas, respeitando-se a opinião dos profissionais da rede de serviços de saúde e representantes da comunidade - atitude essa presente nos discursos oficiais, mas de difícil execução prática. 


\section{Pressupostos teóricos}

Este estudo teve, como um dos referenciais teóricos, a pedagogia histórico-crítica formulada por Saviani (2000) que, segundo o próprio autor, é a articulação de uma proposta pedagógica que tenha o compromisso não apenas de manter a sociedade, mas de transformá-la a partir da compreensão dos condicionantes sociais e da visão de que a sociedade exerce determinação sobre a educação e esta, reciprocamente, interfere sobre a sociedade, contribuindo para sua transformação.

Para a compreensão do papel do médico supervisor e do aprendizado do estudante num cenário de ensino diversificado, a Unidade Básica de Saúde, buscou-se a contribuição da perspectiva sócio-histórica de Vigotski (2001, 1995), que vem sendo utilizada também no campo da Educação Médica, por seus conceitos de mediação, processo de desenvolvimento e de aprendizagem a partir do trabalho profissional.

\section{Objetivo geral}

Analisar a experiência educacional desenvolvida pela disciplina de Pediatria Social e Comunitária, na Atenção Básica, no $4^{\circ}$ ano da Faculdade de Medicina de Botucatu.

\section{Objetivo específico}

Analisar os significados atribuídos pelos médicos supervisores de estudantes em relação aos objetivos da disciplina e aos aspectos relevantes a serem vivenciados pelos estudantes na comunidade.

\section{Métodos}

Foi empregada a metodologia qualitativa de pesquisa, tendo como estratégia o estudo de caso (Yin, 2001), uma escolha determinada pela adequação ao tipo de questão do estudo, de cunho educacional, no campo da formação de profissionais de saúde.

A entrevista representa um instrumento básico de coleta de dados dentro da pesquisa qualitativa, sendo um dos principais utilizado nas pesquisas sociais, pelo seu caráter de interação entre pesquisador e pesquisado (Lüdke, André, 1986).

Existem várias modalidades de entrevista, mas a semiestruturada foi a escolhida no estudo, pois possibilita, ao entrevistado, discorrer sobre o tema proposto com certa liberdade e, ao pesquisador, fazer adaptações para abordar suas hipóteses ou pressupostos (Thiollent, 1987).

\section{População-alvo}

O público-alvo foi constituído de sete médicos supervisores dos alunos em Centros de Saúde e Unidades Básicas de Saúde, com, no mínimo, quatro anos de experiência de ensino de graduação.

\section{Instrumentos e procedimentos de coleta de dados}

As entrevistas foram realizadas pela própria pesquisadora, gravadas com autorização dos entrevistados e transcritas por profissional treinado. Após a transcrição, o material foi lido pelos entrevistados, que aprovaram os textos.

\section{Procedimentos de análise dos dados}

Os materiais estabelecidos para serem analisados, dentro de uma proposta de pesquisa qualitativa, foram as entrevistas e os documentos existentes sobre a disciplina. 
Inicialmente, foi utilizada a técnica de análise de conteúdo de Bardin (1977). Segundo a autora, a primeira etapa é a descrição e a enumeração das características do texto, resumida após tratamento. A segunda etapa é a interpretação e a significação concedida a essas características. A inferência (dedução lógica) é o procedimento intermediário que permite a passagem explícita e controlada da descrição à interpretação.

Na pré-análise, foram realizadas várias leituras flutuantes das transcrições das entrevistas, buscando uma familiarização com as mesmas e seguindo as orientações de Aguiar (2000) e Aguiar e Ozella (2006).

Outra fase da análise foi a leitura que possibilitou um agrupamento de pré-indicadores, pela similaridade e pela complementaridade ou contraposição. Nesse sentido, Aguiar e Ozella (2006, p.8), citando Vigotski, relatam que "quando diversas palavras se fundem numa única, a nova palavra não expressa apenas uma idéia de certa complexidade, mas designa todos os elementos isolados contidos nessa idéia". Essa afirmação reforça o que se observou quando, foi possível, a partir dos pré-indicadores, avançar para indicadores.

Esses são importantes para que seja possível identificar conteúdos que revelem a essência dos sujeitos. Esta fase é a análise propriamente dita, em que é possível identificar as contradições que acontecem, os sentidos e significados que vão se revelando nas falas - é o momento da construção dos núcleos de significação.

\section{Aspectos éticos}

O projeto foi submetido e aprovado pelo Comitê de Ética em Pesquisa Faculdade de Medicina de Botucatu, Unesp.

\section{Resultados e discussão}

\section{A visão dos médicos que participam do curso}

\section{Caracterização dos médicos pediatras supervisores dos estudantes}

Dos médicos que participavam da supervisão de estudantes do quarto ano em UBS e no Centro Saúde-Escola (CSE), sete foram entrevistados. Dentre eles, três têm recebido alunos desde 1994 e puderam, assim, relatar sobre o curso de Pediatria Social e Comunitária do Departamento de Pediatria desde seu início. A análise das falas dos médicos permitiu identificar núcleos de significação, dos quais foram selecionados os mais representativos para os profissionais que atuavam com estudantes na comunidade.

- a importância da diversificação de cenários de ensino, como base para o aluno vivenciar as principais necessidades de saúde da população;

- a importância do perfil do supervisor que identifica, na relação universidade, serviços e comunidade, um espaço de aprendizagem;

- a importância do aprendizado centrado na prática cotidiana em atenção básica;

- o aprendizado dos principais problemas de saúde;

- a experiência na comunidade como oportunidade para vivenciar a complexidade da atenção primária;

- a integralidade no atendimento da criança.

A atenção básica na comunidade foi identificada pelos supervisores como um outro cenário, que não o hospitalar, onde o estudante pudesse aprender o que acontece na comunidade e como a população lida com problemas reais.

O primeiro núcleo de significação que surgiu das falas dos médicos foi "a importância da diversificação de cenários de ensino, como base para o estudante vivenciar as principais necessidades de saúde da população": 
Ao ressaltar a necessidade de conhecer outros cenários que não o hospital, o médico 7 enfatiza, ainda, a importância de o estudante entrar em contato com as principais necessidades de saúde da população, relembrando que, na sua própria formação, não vivenciou esse tipo de oportunidade.

"A gente se formou praticamente sem ter noção do que... De como a população vive [...] Quais são as intercorrências, quais são os problemas que uma comunidade enfrenta e que você vai enfrentar depois que você se forma. [...]". (médico 7)

Autores como Mendes, Silva, Moysés (1996, p.425), ao discutirem sobre a especificidade do ensino na Atenção Primária e junto à Comunidade, destacam que o mais importante não é a mudança simples de cenário, mas, sim, de objetivos educacionais

[...] o objetivo fundamental é organizar a reflexão sobre o trabalho médico, tendo a clínica como fio condutor. A especificidade do atendimento médico nos Centros de Saúde aparece, então, como problema em aberto, problema que vai ser enfrentado pela constante experimentação de modos de trabalho do médico nesses serviços.

Outro tema presente no discurso de todos os médicos, constituindo o segundo núcleo de significação, foi a "importância do perfil do supervisor, que identifica, na relação universidade, serviços e comunidade, um espaço de aprendizagem" - sendo destacada a relevância de ele conhecer o Sistema Único de Saúde (SUS) e seus programas, a comunidade onde trabalha, as possibilidades de cada área, além de perceber a importância da experiência em atenção primária:

“Ele tem que conhecer todos os programas que têm na rede... pra você conseguir orientar o que pode ser feito e o que está sendo feito [...] E eu acho que um outro ponto importante é conhecer a comunidade que ele vai trabalhar". (médico 2)

Em relação ao perfil de supervisor, pode-se recorrer ao trabalho de Batista e Silva (1998), que, ao investigarem os atributos de um bom professor em saúde, identificaram, entre outros, aqueles vinculados à dimensão do domínio científico da área em que atua: saber o conteúdo, pesquisar os assuntos abordados na disciplina, atuar na prática assistencial; ter experiência como profissional de saúde. Nesse sentido, os supervisores de estudantes de pediatria, do presente trabalho, também apontam o valor da experiência profissional e o saber fazer na prática.

"O conhecimento que a gente tem é um conhecimento da prática do dia-a-dia [...]. Eu acho que é o compromisso de estar crescendo junto [...]. Se eu não tiver compromisso com o aprendizado, eu acho que não dá pra ser supervisor". (médico 5)

São valorizadas neste estudo, e também por autores como Batista e Silva (1998), as atitudes do supervisor perante o estudante: saber ouvir, respeitar, incentivar o estudo, estar disponível para dúvidas, ter paciência com o não-saber do aluno, estimular a pesquisa. São atitudes que aparecem na fala de um dos médicos supervisores:

"Na segunda semana, você precisa ter a percepção de que você precisa conversar com eles:

"olha, vocês são ótimos, mas vocês precisam estudar mais. Vocês estão esperando que eu dê tudo. Quer dizer, eu posso discutir ou não, mas eu percebo que eles estão estudando". (médico 5)

Como se trata de supervisores clínicos, há os que destacam a postura frente ao usuário, valorizando a ética, o respeito: 
"Agora, como é que tem que ser essa pessoa? [...] Aberta, disposta a olhar, disposta a se abrir, disposta a... Realmente, olhar cada pessoa que entra pra consultar com você como outra pessoa. Cada pessoa é uma pessoa. Que tem um nome, né?". (médico 7)

Portanto, a supervisão de um médico que está inserido na atenção básica de saúde, que se mostra atento, atuando como mediador para que o aluno aprenda, problematizando as questões identificadas na prática diária, estimula e favorece a inserção do estudante no trabalho médico.

Menin e Menin (2006) valorizam a variabilidade de experiências de aprendizagem que a comunidade oferece, capaz de produzir mudanças nos estudantes, professores e supervisores no processo de ensino-aprendizagem.

Garcia (2001), ao discutir a importância da aproximação do estudante do cotidiano do trabalho do profissional de saúde na atenção primária, cita Góes, que utiliza o referencial de Vygotsky, definindo educar como: " [...] o educar se realiza através de mediações entre sujeitos (dimensão pedagógica) e entre discursos (dimensão discursiva), em situações experimentadas. O trabalho tem por função permitir esta mediação entre sujeitos e seus discursos, em ação, tornando as vivências de aprendizado significativas" (Garcia, 2001, p.91).

Reforçando esses aspectos relacionados com a importância do trabalho, da exposição do estudante a uma situação na comunidade com possibilidades de mediações entre estudante-supervisor, estudantemãe-criança ou estudante-profissional de saúde, percebe-se melhor o potencial que representa especificamente esse cenário. Pois ele oferece diferentes situações de aprendizado, distintas daquelas próprias da academia, ou do ambiente hospitalar ou, ainda, do ambulatório de especialidades.

Para se compreender o papel do professor na comunidade, é essencial observar que, quando o aluno chega à UBS, ele apresenta o que Vigotski (2001) chamou de "nível de desenvolvimento atual" em relação aos vários aspectos considerados relevantes para a sua formação nesse cenário, para os quais já possui uma relativa autonomia para realizá-los (por exemplo, abordagem inicial da mãe). Ao mesmo tempo, o estudante não possui ainda autonomia para realizar várias outras tarefas, necessitando da colaboração de outras pessoas - o que o autor nomeou como "zona de desenvolvimento próximo ou imediato". São processos que se encontram em desenvolvimento e precisam ser estimulados. Nesse contexto, qual seria o papel do médico supervisor? Possibilitar, como mediador, que a aprendizagem do aluno, na comunidade, seja mais eficaz do que aquela possível se estivesse sozinho, criando condições para que o estudante se desenvolva prospectivamente.

O terceiro núcleo de significação é o da "importância do aprendizado centrado na prática cotidiana em atenção básica".

Esse aprendizado foi dos mais salientados pelos médicos. Um deles destaca os diferentes momentos de aprendizagem como: o aprender a dinâmica da UBS, que é bastante complexa, além dos problemas de saúde mais frequentes; e a prevenção e promoção da saúde; conhecer a postura do estudante em relação ao serviço público; otimizar a relação estudante-usuário, e, por fim, incorporar uma visão integral da família e da criança.

Em relação à aprendizagem centrada na prática, os médicos assim se expressaram:

“você consegue aprender lá no posto de saúde. Tem puericultura e tem as doenças que exigem bastante retornos, assim... E alguns alunos pegam, assim, a evolução das doenças. [...] E dá pra aprender em cima do caso, né?". (médico 3)

Nos momentos de aprendizagem, cita-se o aprendizado da dinâmica de trabalho:

"Primeira coisa, quando o aluno chega, é conhecer a unidade. Onde fica a pós-consulta, onde fica a pré-consulta, onde fica o arquivo... A assistente social, onde fica a cozinha, né? Onde fica a inalação... [...] Primeira coisa, eu explico é o funcionamento [...]. Pra eles verem todos os passos que o paciente faz dentro da unidade básica de saúde". (médico 1) 
Sabe-se que, no dia a dia, com o tempo, em qualquer local de trabalho, o ser humano consegue aprender.

O conhecimento do cotidiano da unidade de saúde, as tarefas ali desenvolvidas são, portanto, os primeiros passos para que o estudante perceba a realidade deste cenário de aprendizagem e de cuidado. O trabalho em uma UBS, desenvolvido no cotidiano, segue alguns princípios. Nessa pesquisa, aprofundou-se como se dá esse aprendizado. A percepção, através da sensorialidade, pode estimular a atenção, o raciocínio, os sentimentos. Desse modo, a orientação do educador pode favorecer o desenvolvimento do indivíduo. Nesse sentido, Leontiev (1996), na mesma perspectiva de Vigotski (2001), afirma que o psiquismo é um produto da experiência sócio-histórica humana. Ele está determinado pelas condições sociais nas quais vivem os indivíduos concretos, isto é, reproduz certas características da realidade material e social com a qual esses indivíduos interagem.

O autor afirma, ainda, que, na base do desenvolvimento dos significados e sentidos, está o conteúdo sensível (sensações, imagens de percepção, representações). Deste modo, como a vida cotidiana se constitui numa esfera do ser social, pode-se dizer que o psiquismo humano, de forma geral, sintetiza ou reproduz certas características da cotidianidade. Em suma, pode-se, então, falar em determinadas formas de pensamento, sentimento e ação tipicamente cotidianos (Rossler, 2004).

Para entender, também, o aprendizado baseado na prática, a teoria da vida cotidiana de Agnes Heller tem sua contribuição. Para Heller $(1989,1984)$, a formação dos indivíduos começa sempre nas esferas da vida cotidiana. Esse processo de formação se inicia já no momento de seu nascimento e da inserção no universo cultural humano, e se estende por toda a vida.

Portanto, para aprender sobre atuação na atenção básica é preciso vivenciar essa experiência cotidiana. Entre as várias características do cotidiano, destaca-se aquela que pode contribuir na compreensão do trabalho em uma Unidade Básica de Saúde, enquanto aprendizado, para quem, na vida profissional, irá atuar nessa mesma prática. Esta característica do aprendizado no cotidiano é a imitação, quando o estudante vivencia diferentes formas de os pediatras se comunicarem com as mães em situações de consulta. A imitação permite aprendizados sobre anamnese e exame físico, como destacado por outro médico:

"Puericultura: a gente vai fazer o atendimento, a gente vai ver como é que tira a história, como e o que é que a criança come, o que é que a gente orienta, como é que está o desenvolvimento, como é que a gente examina. Então ele vai fazer, hoje, uma puericultura de bebezinho. Amanhã, outra puericultura. No primeiro dia, ele vai com medo de pegar o nenezinho. Não sabe como é que faz o exame neurológico. No final do último... Do mês, ele já está com uma prática boa de fazer avaliação de desenvolvimento neurológico". (médico 5)

Observa-se que o aprendizado, no dia a dia, depende de diferentes variáveis, de diferentes características do cotidiano, sintetizadas no dizer de Schraiber (1998, p.384):

Quando falamos do exercício de aplicar o conhecimento no cotidiano ou mesmo o de praticar técnicas aprendidas na escola, estaremos diante daquela parte da prática em saúde que trata da relação do profissional com a biodiversidade dos fenômenos em saúde e que se perpassa com a diversidade da vida social. Assim, como é freqüente se dizer que cada caso de paciente é um caso, diz-se que o caso típico só aparece nos livros e que na prática profissional todos os casos sempre se apresentam com variações da norma. Para o médico o saber da ciência é importante, mas principalmente como converter tudo isto no saber operante, como comunicar isto ao paciente, ouvindo e acolhendo suas dúvidas e angústias.

Outro núcleo de significação destacado pelos médicos supervisores aponta "O aprendizado dos principais problemas de saúde" como fundamental no ensino na atenção básica, constituindo-se no quarto núcleo de significação. 
“Então um aluno, na unidade básica de saúde, ele pode ver as doenças comuns que aparecem todos os dias e que podem ser tratadas [...] Casos também, doenças com um pouco de mais complexidade que podem ser atendidas e acompanhadas num posto". (médico 1)

$\mathrm{Na}$ análise documental dos programas da disciplina de Pediatria Social na Comunidade, é destacado o aprendizado dos problemas mais prevalentes de saúde da criança. Como o ensino na UBS é realizado no atendimento da demanda, espera-se que o estudante entre em contato, conheça e valorize os casos de puericultura e as doenças de maior frequência, bem como sua prevenção. Os espaços do hospital universitário e dos ambulatórios de especialidade, ao cumprirem seu papel de centro de referência para o sistema de saúde vigente, deixaram de ser os locais adequados para o ensino das doenças prevalentes, pois neles são atendidos os usuários cujos problemas de saúde necessitam de um arsenal tecnológico e de profissionais cada vez mais especializados.

Campos (1999) destaca que o Brasil precisa dos hospitais terciários, mas esses são inadequados para o ensino de graduação de Medicina e Enfermagem. São serviços ótimos para a residência, pósgraduação e realização de pesquisa de ponta. Mas não estariam, segundo o autor, servindo para formar médicos com capacidade e responsabilidade clínica integral.

Marcondes (1998), em editorial da revista Pediatria (São Paulo), destacava que, em estudo envolvendo 19 escolas médicas do estado de São Paulo, o ensino da atenção primária estava presente em sete escolas das nove que responderam ao questionamento. Os departamentos mais envolvidos eram os de Medicina Preventiva e Pediatria.

Afirmo que o pediatra é um médico diferente de qualquer outro profissional de Medicina. Trabalhando com crianças e mães, eles têm uma enorme percepção sobre os fatores ambientais e relações humanas. Lidando com pessoas em crescimento e desenvolvimento, os pediatras enfatizam a Medicina geral e têm uma atenção aguçada para o preventivo na sua prática médica. (Marcondes, 1998, p.171)

É do senso comum a concepção de que, na unidade básica, só existem casos e situações simples, o que não corresponde à realidade, e os médicos supervisores fizeram essa constatação, que se constituiu no quinto núcleo de significação, o da "experiência na comunidade como oportunidade para vivenciar a complexidade da atenção primária".

"A complexidade da inter-relação que existe entre a queixa física que a criança vem apresentando e a relação desta criança, deste pacientinho com a comunidade, com a família, com a escola, ou... A relação disso com a forma como os pais estão experimentando a sua situação naquela mesma época... O que é que está acontecendo dentro da família... Como é que a criança está se desenvolvendo...". (médico 7)

"É de outra natureza as queixas que vêm pro consultório na comunidade. É um ser humano se expressando em toda a sua extensão, toda a sua totalidade". (médico 7)

A citação acima é um exemplo de que aquela falsa ideia de apenas "casos simples" precisa ser problematizada. Seja através da vivência do estudante nesse cenário, além do aprimoramento de sua capacidade de escuta, de observação e das discussões com os supervisores, que reconhecem essa complexidade e buscam mostrá-la.

Schraiber e Mendes-Gonçalves (2000) explicitam como o conceito de atenção primária tem sido associado a uma assistência de baixo custo, tratando-se de um serviço simples e quase sempre com poucos equipamentos, contendo uma prática fadada a ser uma "medicina simplificada". Esses autores citam Donnangelo e Pereira (1979) para explicar a origem histórica da prestação de serviços, que destinava-se a ampliar a cobertura dos serviços para a população mais carente e excluída, estendendo a assistência médica de forma simplificada e barata. Mas, as enormes dificuldades na extensão dos 
serviços, ou, até mesmo, para manter a cobertura, tornaram-se algo muito mais complexo do que se imaginava.

Schraiber e Mendes-Gonçalves (2000) explicam que, na atenção primária, muitas situações cotidianas constituem casos instrumentalmente simples e que, por vezes, são patologicamente mais fáceis, mas que nem por isso deixam de envolver uma grande complexidade assistencial.

O sexto núcleo de significados que emergiu das falas dos médicos foi $o$ "da integralidade no atendimento em pediatria". Esses destacaram, como importante aprendizado para o estudante: a visão integral da criança e da família, a sua não-fragmentação, a possibilidade de um enfoque que não seja centrado só na doença ou no diagnóstico, mas, também, no indivíduo, no ser humano.

"No mesmo dia, a gente vê criança que foi só para a puericultura, criança que é asmática, criança com retardo de desenvolvimento, criança que você tem que orientar a alimentação, criança que você tem que fazer orientação ambiental, criança que você, às vezes, precisa de medicamento. Essa variedade acaba, assim, deixando eles fascinados, né? Como que o médico da unidade tem que raciocinar durante o período para ele resolver diversas coisas e pensar em tudo. E ver a orientação, e ver a parte de higiene mental da criança, e ver a parte do vínculo da criança, e ver com resolve o problema da creche, e ver se está inserida ou se não está inserida". (médico 5)

"Que ele veja um ser humano. Não compartimentalizado, não dividido em especialidades, não dividido em... Diagnósticos..".. (médico 7)

Seis médicos supervisores relataram como fundamental que o estudante vivencie o vínculo que existe entre o profissional e a população de cada área de abrangência. Este vínculo é possível através da interação e, dessa forma, a comunicação deve ser bastante valorizada.

“Então é diferente quando você atende o paciente a primeira vez e se você atende ele há dez anos, né?. Então você também tem isso: mostrar que você também faz vínculo com o paciente. Às vezes o paciente pergunta, tem liberdade de falar as coisas. Ou, às vezes, nem sempre o paciente vai falar tudo na primeira vez. Às vezes vai falar numa segunda vez [...] devido a que isso é importante no $4^{\circ}$ ano, né? Ele vivencia esse vínculo". (médico 1)

As práticas pediátricas, identificadas por meio do discurso dos profissionais, revelam que, para os médicos, o cuidado com a criança e sua família é o ponto central da consulta, pois qualifica o trabalho do profissional e fortalece o aprendizado de uma clínica ampliada.

"Quando eu chego na sala, eu falo, "oi, tudo bem? Como está a senhora?" Trato pelo nome a mãe, trato pelo nome as crianças... Os alunos que vão lá, eu acho que percebem isso também... [...] Faz sete anos que eu estou lá. Eu acho que esse tempo lá de convivência com a população é o essencial pra um posto de saúde ou um programa de médico da família atuar. Fazer com que aquele posto de saúde se torne uma referência, eu acho que é essencial". (médico 3)

"Você conhece todo mundo, as famílias, a dinâmica, o local que eles vivem né? Porque a gente vai na escola, porque a gente vai na creche... Então, tudo isso ajuda nessa visão integral da criança mesmo? Ela inserida onde ela vive, onde ela estuda, onde ela brinca...". (médico 5)

A relação estudante-usuário aparece como um aprendizado importante na comunidade, a partir da vivência com um profissional que tenha um bom vínculo com sua população. 


\begin{abstract}
"A questão da postura, da... Do respeito... Naquela hora que a gente fica meio aborrecido com o que ela fala [...]. Então é essa coisa da empatia, né? Quer dizer, tentar se colocar no lugar dela pra entender melhor porque é que ela faz ou deixa de fazer isso ou aquilo, né? E, de um modo geral, eles (os estudantes) têm tido, assim... Eu acho que eles têm atendido, assim, com carinho, com atenção, com postura de médico mesmo". (médico 6)
\end{abstract}

Franco (2001), ao discutir a qualidade na prática pediátrica em relação ao modelo pedagógico que privilegia o ensino tradicional, relata que os pediatras participantes de seu estudo reconheceram que a escola médica não propiciou a ampliação do núcleo de atuação do médico, onde a clínica privilegiou o enfoque do objeto corporificado, ou seja, apenas o enfoque no biomédico. Durante o processo formativo naquele modelo, o estudante estaria impedido de perceber que o processo de atenção e cuidado é também tecnologia, e que deve ser aprimorado com a incorporação de elementos como o vínculo, a responsabilização, a troca e a comunicação.

No presente trabalho, o que foi identificado no discurso de dois médicos supervisores, sobre a clínica ampliada e sobre o vínculo, reveste-se de grande importância, enquanto possibilidade de uma formação diferente para os estudantes de graduação inseridos na atenção primária nos serviços de saúde em Botucatu.

Alguns médicos destacaram a postura do estudante um tanto quanto preconceituosa em relação ao serviço público, e a possibilidade de mudança ao atuar na Atenção Básica:

"Então eles começam a ver que o sistema de saúde municipal, ele é, em alguns momentos, dependente do serviço da universidade, mas que ele tem uma organização própria [...]. E passando pelos diferentes profissionais, eles vêem a atuação. Eu acho que eles mudam a postura e passam pra uma valorização maior do sistema público". (médico 5)

Em relação aos temas destacados pelos médicos como essenciais na formação dos futuros profissionais, estão referidos nas Diretrizes Curriculares para os Cursos de Medicina (Brasil, 2001, p.38), que apontam para uma

[...] formação generalista, humanista, crítica e reflexiva, capacitado a atuar, pautado em princípios éticos, no processo de saúde-doença, em seus diferentes níveis de atenção, com ações de promoção, prevenção, recuperação e reabilitação à saúde, na perspectiva da integralidade da assistência, com senso de responsabilidade social e compromisso com a cidadania, como promotor da saúde integral do ser humano.

Nessa perspectiva, o papel mediador do supervisor dos estudantes, dos outros membros da equipe de saúde e do docente responsável, segundo Vigotski (2000), é fundamental para que o estudante alcance aprendizagens próprias desse cenário, como é o caso da clínica ampliada, que pode estar garantida, desde que essa seja a intencionalidade de todos os supervisores.

\title{
Considerações finais
}

A construção do ensino de Pediatria na Comunidade, na FMB, realizou-se, ao longo do tempo, dentro de um processo histórico, em conjunto com as experiências de integração docente-assistencial do então Departamento de Saúde Pública, uma vez que os docentes formuladores dessa disciplina acreditaram na introdução de um novo cenário de ensino - a Comunidade - e que hoje, consolidado, mereceu ser estudado no presente trabalho. Deve-se mencionar que, segundo Kisil e Chaves (1994), os Projetos "Uma Nova Iniciativa na Formação dos Profissionais de Saúde" (Projetos UNI) e, mais recentemente, o Programa de Incentivo a Mudanças Curriculares nos Cursos de Medicina (Promed) 
(Brasil, 2002) e o Programa Nacional de Reorientação da Formação em Saúde (Pró-Saúde) (Brasil, 2005) têm sido importantes políticas indutoras e incentivadoras de um processo de mudança da formação dos profissionais da área de saúde e suas práticas, exigindo dedicação, tanto dos profissionais da academia como dos serviços e comunidade.

Foi possível identificar, pela análise dos núcleos de significação, que o ensino de pediatria na comunidade tem contribuído para que alguns dos objetivos traçados pelos docentes formuladores fossem atingidos, como: o de conhecer a realidade das famílias consultadas, das escolas, projetos e creches, além das doenças mais prevalentes, medidas de prevenção e promoção da saúde.

O presente trabalho mostrou que, no ensino da Atenção Básica, se faz necessária uma produção sistematizada de conhecimento e de avaliações contínuas, que possibilitem a superação, por exemplo, da falsa dicotomia entre teoria e prática.

Os médicos destacaram que a Atenção Básica, como cenário de ensino, favorece a formação de um profissional conhecedor das necessidades de saúde de uma população, o que vem ao encontro de uma das propostas presentes nas Diretrizes Curriculares Nacionais, para os cursos de medicina.

O desafio colocado é o de como inovar e integrar, efetivamente, esse cenário, de modo transversal, em todo o curso de medicina.

Atualmente, as pesquisas em Educação Médica tornam-se cada vez mais necessárias. Serão elas que, nos momentos de avaliação da e na Escola Médica, orientarão sua trajetória na busca concreta de cumprir seu papel social.

\section{Colaboradores}

As autoras Alice Yamashita Prearo, Águeda Beatriz Pires Rizzato e Sueli Terezinha Ferreira Martins participaram integralmente de todas as etapas da elaboração do artigo.

\section{Referências}

AGUIAR, W.M.J. Reflexões a partir da psicologia sócio-histórica sobre a categoria consciência. Cad. Pesqui., s/v, n.110, p.125-42, 2000.

AGUIAR, W.M.J.; OZELLA, S. Núcleos de Significação como Instrumento para Apreensão da Constituição dos Sentidos. Psicol. Cienc. Prof., v.26, n.2, p.222-45, 2006.

BARDIN, L. Análise de conteúdo. Lisboa: Edições 70, 1977.

BATISTA, N.A.; SILVA, H.S.S. O professor de medicina: conhecimento, experiência e formação. São Paulo: Loyola, 1998.

BRASIL. Ministério da Saúde. Ministério da Educação. Secretaria de Gestão do Trabalho e da Educação na Saúde. Departamento de Gestão da Educação em Saúde. Pró-saúde: programa nacional de reorientação da formação profissional em saúde. Brasília: Ministério da Saúde/Ministério da Educação, 2005.

Ministério da Saúde. Ministério da Educação. Secretaria de Políticas de Saúde. Secretaria de Ensino Superior. Programa de Incentivo a Mudanças Curriculares nos Cursos de Medicina. Uma nova Escola Médica para um novo Sistema de Saúde. Brasília: Ministério da Saúde/Ministério da Educação, 2002. 
BRASIL. Ministério da Educação. Conselho Nacional de Educação. Câmara de Educação Superior. Resolução CNE/CES n4, de 7 de novembro de 2001. Institui diretrizes curriculares nacionais do curso graduação em medicina. Brasília: Ministério da Educação, 2001.

BULCÃO, L.G. O ensino médico e os novos cenários de ensino-aprendizagem. Rev. Bras. Educ. Med., v.28, n.1, p.61-72, 2004.

CAMPOS, G.W.S. Papel da rede de atenção básica em saúde na formação médica: diretrizes. 2005. Disponível em: <http://www.abemeducmed.org.br/ posicionamento_abem/doc_prof_gastaopdf>. Acesso em: 1 ago. 2007. Educação médica, hospitais universitários e o Sistema Único de Saúde. Cad. Saude Publica, v.15, n.1, p.187-93, 1999.

CYRINO, E.G. et al. O programa: história, princípios e estratégias. In: CYRINO, E.G. (Ed.). A universidade na comunidade: educação médica em transformação. Botucatu: Núcleo de Apoio Pedagógico, Faculdade de Medicina de Botucatu, 2005. p.21-31.

DONNANGELO, M.C.F.; PEREIRA, L. Saúde e sociedade. 2.ed. São Paulo: Duas Cidades, 1979.

FEUERWERKER, L.C.M. Mudanças na educação médica e residência médica no Brasil. Interface - Comunic., Saude, Educ., v.2, n.3, p.51-71, 1998.

FRANCO, S.C. A qualidade possível: o pediatra e o processo de decisão médica nos serviços públicos de saúde. 2001. Tese (Doutorado) - Faculdade de Ciências Médicas, Universidade Estadual de Campinas, Campinas. 2001.

GARCIA, M.A.A. Saber, agir e educar: o ensino-aprendizagem em serviços de saúde. Interface - Comunic., Saude, Educ., v.5, n.8, p.89-100, 2001.

HELLER, A. Cotidiano e história. Rio de Janeiro: Paz \& Terra, 1989.

Sociologia de la vida cotidiana. 4.ed. Barcelona: Península, 1984.

KISIL, M.; CHAVES, M.M. Programa UNI: uma nova iniciativa na educação dos profissionais de saúde. Battle Creek: Fundação W. K. Kellogg, 1994.

LEONTIEV, A.N. Artigo de introdução sobre o trabalho criativo de L. S. Vigotski. In: VIGOTSKI, M.L.S. (Org.). Teoria e método em psicologia. Trad. Claudia Berlinger. São Paulo: Martins Fontes, 1996. p.425-70.

LÜDKE, M.; ANDRÉ, M.E.D.A. Pesquisa em educação: abordagens qualitativas. São Paulo: EPU, 1986.

MARCONDES, E. A pediatria e o ensino da atenção primária. Pediatria (São Paulo), v.20, n.3, p.171, 1998.

MENDES, R.T.; SILVA, P.E.M.R.; MOYSÉS, M.A.A. Aprendizado de medicina nos serviços de atenção primária e no contato com a comunidade. Medicina, v.29, n.4, p.420-8, 1996.

MENIN, S.; MENIN, R.P. Community-based medical education. Clin. Teach., v.3, n.2, p.90-6, 2006.

PONTES, A.L.M.; REGO, S.; SILVA JUNIOR, A.G. Saber e prática docente na transformação do ensino médico. Rev. Bras. Educ. Med., v.30, n.2, p.66-75, 2006.

PREARO, A.Y. O ensino de pediatria na atenção básica em saúde: entre as fronteiras do modelo biomédico e a perspectiva da integralidade do cuidado - um estudo de caso. 2007. Tese (Doutorado) - Faculdade de Medicina de Botucatu, Universidade Estadual Paulista, Botucatu. 2007. 
PUGA, T.F.; BENGUIGUI, Y. Ensino de Pediatria em escola de medicina da América Latina. Washington: Organização Panamericana de Saúde, 2003. Disponível em: <www.paho.org/spanish/ad/fch/ca/si-alape.portugues.pdf>. Acesso em: 1 nov. 2010.

ROSSLER, J.H. O desenvolvimento do psiquismo na vida cotidiana: aproximações entre a psicologia de Alexis N. Leontiev e a teoria da vida cotidiana de Agnes Heller. Cad. CEDES, v.24, n.62, p.100-16, 2004.

SAVIANI, D. Pedagogia histórico crítica: primeiras aproximações. 7.ed. Campinas: Autores Associados, 2000.

SCHRAIBER, L.B. Educação e serviços: a perspectiva da Educação Permanente na Saúde. In: MARCONDES, E.; GONÇALVES, E.L. (Orgs.). Educação médica. São Paulo: Sarvier, 1998. p.382-6.

SCHRAIBER, L.B.; MENDES-GONÇALVES, R.B. Necessidades de saúde e atenção primária. In: SCHRAIBER, L.B.; NEMES, M.I.B.; MENDES-GONÇALVEZ, R.B. (Orgs.). Saúde do adulto: programas e ações na unidade básica. São Paulo: Hucitec, 2000. p.29-47.

THIOLLENT, M. Critica metodológica, investigação social e enquete operária. São Paulo: Polis, 1987.

VIGOTSKI, L.S. A construção do pensamento e da linguagem. São Paulo: Martins Fontes, 2001.

A formação social da mente: o desenvolvimento dos processos psicológicos superiores. 6.ed. São Paulo: Martins Fontes, 2000.

. Método de investigación. In: MARTINEZ-MARIN, F. Obras escogidas III. Trad. Lydia Kuper. Madrid: Visor, 1995. p.47-96.

YIN, R.K. Estudo de caso: planejamento e métodos. 2.ed. Porto Alegre: Bookman, 2001.

PREARO, A.Y.; RIZZATO, Á.B.P.; MARTINS, S.T.F. La enseñanza de la pediatría en atención básica en salud; los límites entre el modelo biomédico y la perspectiva de la atención integral: una visión de los supervisores médicos. Interface - Comunic., Saude, Educ., v.15, n.39, p.1039-51, out./dez. 2011.

El estudio presenta una contribución de la pediatría social y comunitaria en el $4^{\circ}$ año los de graduación en medicina de la Facultad de Medicina de Botucatu, Universidade Estadual Paulista, Brasil. Se utilizó una metodología de investigación cualitativa, con una estrategia de estudio de caso. El análisis se basó en el enfoque histórico-social, apoyado por los estudios de Vigotsky. Se encontró lo que los supervisores de disciplina consideran como aprendizaje relevante a su contribución en el proceso de mediación para que los estudiantes aprendan sobre el proceso de trabajo en los cuidados básicos, lo que no podrían lograr por sí solos.Las entrevistas con los médicos revelan núcleos de significación que son comune: la importancia de los diferentes entornos de enseñanza, el aprendizaje de los principales problemas de salud, integración en el cuidado del niño, con énfasis en el vínculo y oportunidad del estudiante para aprender sobre promoción de la salud.

Palabras clave: Educación médica. Pediatría. Atención primaria de salud. Estudio de caso. 